\title{
Lower risk of hypoglycaemia and greater odds for weight loss with initiation of insulin detemir compared with insulin glargine in Turkish patients with type 2 diabetes mellitus: local results of a multinational observational study
}

Taner Damci ${ }^{1 *}$, Rifat Emral ${ }^{2}$, Anne Louise Svendsen ${ }^{3}$, Tanzer Balkir ${ }^{4}$, and Jiten Vora ${ }^{5}$ On behalf of the SOLVE ${ }^{\mathrm{TM}}$ study group

\begin{abstract}
Background: The purpose of this analysis is to evaluate the safety and effectiveness of insulin initiation with once-daily insulin detemir (IDet) or insulin glargine (IGlar) in real-life clinical practice in Turkish patients with type 2 diabetes mellitus (T2DM).

Methods: This was a 24-week multinational observational study of insulin initiation in patients with T2DM. Results: The Turkish cohort $(n=2886)$ included 2395 patients treated with IDet and 491 with IGlar. The change in glycosylated haemoglobin $\left(\mathrm{HbA}_{1 c}\right)$ from the pre-insulin levels was $-2.21 \%$ [95\% confidence interval $\left.(\mathrm{Cl})-2.32,-2.09\right]$ in the IDet group and $-1.88 \%[95 \% \mathrm{Cl}-2.17,-1.59]$ in the IGlar group at the final visit. The incidence rate of minor hypoglycaemia increased in both groups from the pre-insulin to the final visit $(+0.66$ and +2.23 events per patient year in the IDet and IGlar groups, respectively). Weight change in the IDet group was $-0.23 \mathrm{~kg}[95 \% \mathrm{Cl}-0.49,0.02 \mathrm{~kg}]$, and $+1.55 \mathrm{~kg}[95 \% \mathrm{Cl} 1.11,2.00 \mathrm{~kg}]$ in the IGlar group. Regression analysis with adjustment for previously identified confounders (age, gender, duration of diabetes, body mass index, previous history of hypoglycaemia, microvascular disease, number and change in oral anti-diabetic drug therapy, $\mathrm{HbA}_{1 c}$ at baseline and insulin dose) identified an independent effect of insulin type (IDet versus IGlar) with a risk of at least one episode of hypoglycaemia (odds ratio (OR): 0.33 [95\% Cl 0.21, 0.52], p <0.0001), and weight loss $\geq 1 \mathrm{~kg}$ (OR: 1.75 [95\% Cl 1.18, 2.59], $p=0.005$ ), but not on $\mathrm{HbA}_{1 \mathrm{c}}(+0.05 \%[95 \% \mathrm{Cl}-0.15,0.25 \%], \mathrm{p}=0.6)$.
\end{abstract}

Conclusions: Initiation of basal insulin analogues, IDet and IGlar, were associated with clinically significant glycaemic improvements. A lower risk of minor hypoglycaemia and greater odds of weight loss $\geq 1 \mathrm{~kg}$ was observed with IDet compared with IGlar.

Trial registration: NCT00825643 and NCT00740519

Keywords: Insulin detemir, Insulin glargine, Basal insulin, Type 2 diabetes, Weight loss, Hypoglycaemia

\footnotetext{
* Correspondence: tdamci@gmail.com

'Department of Endocrinology, Diabetes and Metabolism, Cerrahpasa

Medical School, Istanbul University, 34363 Istanbul, Turkey

Full list of author information is available at the end of the article
} 


\section{Background}

Many patients with type 2 diabetes mellitus (T2DM) ultimately require insulin to maintain glycaemic control. Nonetheless, there is still considerable debate regarding which insulin regimens are optimal to start the treatment cascade of the disease [1]. Basal insulin is a widely used treatment option for patients with T2DM at various stages of disease progression [2]. Basal insulin formulations have been continuously improved over the years and have become widely used as they have many pharmacodynamic and pharmacokinetic advantages over neutral protamine Hagedorn (NPH) insulin including a longer duration of action, reduced variable absorption profiles and a reduced marked peak effect [3]. Insulin detemir and insulin glargine are widely used as add-on therapies for patients not responding to oral anti-diabetic drug (OAD) regimens, but there are few studies directly comparing the two insulin analogues in routine care [4-6].

The primary objective of this international observational study, SOLVE ${ }^{\mathrm{sm}}$, was to evaluate the safety and effectiveness of once-daily insulin detemir or glargine in a real-life clinical setting in patients with T2DM failing OAD therapy. The following is a sub-analysis of the local SOLVE $^{\mathrm{Tn}}$ cohort in Turkey, the first observational study comparing the effects of once-daily insulin detemir with insulin glargine initiation as add-on therapy to OAD in patients with T2DM.

\section{Methods}

\section{Study design}

The present evaluation is a sub-analysis of the SOLVE $\mathrm{E}^{\mathrm{mm}}$ study (clinical trial numbers NCT00825643 and NCT 00740519). This study was a 24-week, non-interventional, international, multi-centre, open-label, prospective study of insulin detemir initiation in patients with T2DM treated with one or more OADs. SOLVE ${ }^{\mathrm{TM}}$ was conducted in 10 countries: Canada, China, Germany, Israel, Italy, Poland, Portugal, Spain, the UK and Turkey. The study was conducted in accordance with the Declaration of Helsinki and Guidelines for Good Pharmacoepidemiology Practice $[7,8]$. Ethical approval was obtained from local institutional review boards or independent ethics committees prior to commencement of the study in each of the participating countries [9]. Initiation of insulin therapy was entirely at the discretion of the treating physician according to local clinical practice, and the study enrolled and evaluated patients for whom this decision had already been made. Results from the global study cohort have been previously published [10,11].

In Turkey, the national regulatory requirements led to the inclusion of patients prescribed either insulin detemir or insulin glargine at least once daily, and thus provided an opportunity to compare the effects of the two insulin analogues in patients with T2DM. Data were collected during three routine clinic visits: a baseline visit immediately upon initiating treatment with oncedaily insulin detemir or insulin glargine, an interim visit at 12 weeks, and a final visit at 24 weeks. Any procedures during the study period with regard to clinical care delivered were entirely at the discretion of the participating physician and the local practice in the investigating centre.

\section{Patients}

The Turkish patient cohort was enrolled between April 2008 and October 2009. The inclusion and exclusion criteria for the global SOLVE ${ }^{\mathrm{m}}$ study have been described elsewhere [11]. Patients already receiving one or more OADs and commencing treatment with either insulin detemir or insulin glargine within the previous 3 months could be enrolled in the study at the discretion of the investigator. Patients receiving insulin treatment for more than 3 months were excluded. Children below the age of 6 years and female patients who were pregnant, breastfeeding or intending to become pregnant within 6 months of the study initiation or who were not using adequate contraceptive methods were also excluded from the study. People with known or suspected allergy to insulin detemir or insulin glargine and those receiving glucose-lowering treatment other than diet, exercise or OAD before basal insulin therapy were also excluded. To limit selection bias, participating physicians were instructed to enrol patients on a consecutive basis until each site met the recruitment targets.

Patients could withdraw from the study at any time without giving any specific reason. Those patients who withdrew consent were not initiated on insulin at the baseline visit, and those who had an informed consent date after the baseline visit date, were excluded from the Turkish cohort.

\section{Endpoints}

The primary goal for safety assessment was to evaluate the incidence of serious adverse drug reactions (SADRs), including major hypoglycaemic events, while using oncedaily insulin detemir or once-daily insulin glargine in routine clinical practice. Safety evaluation also included the incidence of all daytime and nocturnal hypoglycaemic events and all other reported adverse drug reactions (ADRs).

ADRs were defined as any event for which a causal relationship to insulin detemir or insulin glargine was suspected, from the time the patient gave informed consent until the patient completed the study. The event was defined as serious if it resulted in any of the following: death, a life-threatening experience, in-patient hospitalization or prolongation of existing hospitalization for more than 24 hours, a persistent or significant disability/ 
incapacity, a congenital anomaly/birth defect, or another important medical event that required medical or surgical intervention to prevent one of the outcomes listed in this definition. In this study, all episodes of major hypoglycaemia were considered to be SADRs.

All episodes of hypoglycaemia were self-reported. Major hypoglycaemia was defined as any hypoglycaemic event requiring assistance from a third party. Minor hypoglycaemia was defined as a blood glucose measurement $<56 \mathrm{mg} / \mathrm{dL}(3.1 \mathrm{mmol} / \mathrm{L})$ with or without symptoms. The period of recall for major hypoglycaemia and minor hypoglycaemia was 12 weeks and 4 weeks prior to the follow-up visit, respectively. Hypoglycaemic events were classified as nocturnal, if they occurred between bedtime and getting up the next morning.

Efficacy was assessed through the evaluation of glycosylated hemoglobin $\left(\mathrm{HbA}_{1 \mathrm{c}}\right)$ and fasting blood glucose (FBG) (mean, change from baseline). Other secondary endpoints included: seven-point self-monitoring of blood glucose (SMBG) profile (pre- and post-breakfast, pre- and post-lunch, pre- and post-dinner, at night), body weight, waist circumference, waist-to-hip ratio, systolic and diastolic blood pressure, total cholesterol, low-density lipoprotein cholesterol, high-density lipoprotein cholesterol, triglycerides and insulin dose, and the use of OADs, antihypertensive drugs and lipid-lowering drugs.

\section{Statistical analysis}

Patients using insulin detemir or insulin glargine at least once daily and reporting safety information to the physician were included in the analyses of adverse drug reactions (ADRs) and hypoglycaemia (Full Analysis Set [FAS]). Analyses of $\mathrm{HbA}_{1 \mathrm{c}}$, blood glucose and lipid profiles were based on a subset of patients with at least one FBG, $\mathrm{HbA}_{1 \mathrm{c}}$, weight measurement or record of hypoglycaemia at both baseline and final visit (Efficacy Analysis Set [EAS]).

Continuous variables are summarized with descriptive statistics (mean, standard deviation, 95\% confidence interval $(\mathrm{CI})$ ). Categorical variables are reported in frequency tables $(\mathrm{N}, \%)$. Statistical comparisons of pre- and post-insulin initiation values were performed with paired t-tests for continuous variables. Wilcoxon signed-rank test was used to compare the rates of hypoglycaemic events at baseline and final visit.

Regression models were used to evaluate the effect of insulin type on final-visit $\mathrm{HbA}_{1 \mathrm{c}}$ (general linear model), occurrence of at least one episode of hypoglycaemia from baseline to study end, and weight loss of at least $1 \mathrm{~kg}$ (logistic regression models). The weight model included all parameters identified as being significant predictors of weight loss $\geq 1 \mathrm{~kg}$ in the analyses of the global SOLVE $^{\mathrm{Tm}}$ cohort (data on file). This included gender, body mass index (BMI) categories $\left(<25 \mathrm{~kg} / \mathrm{m}^{2}, 25\right.$ to $<30 \mathrm{~kg} / \mathrm{m}^{2}$,
30 to $<35 \mathrm{~kg} / \mathrm{m}^{2}$ and $\geq 35 \mathrm{~kg} / \mathrm{m}^{2}$ ), number of OADs at baseline and baseline $\mathrm{HbA}_{1 \mathrm{c}}$. The $\mathrm{HbA}_{1 \mathrm{c}}$ and hypoglycaemia models included all parameters identified as being significant predictors either of $\mathrm{HbA}_{1 \mathrm{c}}$ at final visit or the occurrence of at least one episode of hypoglycaemia in analyses of the global cohort. These parameters included age categories ( $<50$ years, $50-75$ years in 5-year intervals, and $\geq 75$ years), diabetes duration (in quartiles), BMI categories (as presented above), previous history of hypoglycaemia or microvascular disease, number and change in OAD therapy at the time of insulin initiation, $\mathrm{HbA}_{1 \mathrm{c}}$ at baseline and insulin dose (IU in quartiles) [12]. All regression models included the additional variable of the insulin type, to denote treatment with either insulin detemir or insulin glargine.

For the evaluation of $\mathrm{HbA}_{1 \mathrm{c}}$ and hypoglycaemia, two sensitivity analyses were performed. The first included a previous history of macrovascular disease in addition to the above-mentioned parameters. The second was a more basic model only adjusting for duration of diabetes, previous history of hypoglycaemia and baseline $\mathrm{HbA}_{1 \mathrm{c}}$. The results of the sensitivity analyses are available in Additional file 1.

All analyses used two-sided tests with the criteria set at $\alpha=0.05$.

\section{Results}

A total of 2395 patients were enrolled in the insulin detemir group. Thirteen subjects were excluded for the following reasons: no insulin treatment $(n=4)$, informed consent date after baseline visit date $(\mathrm{n}=8)$ and withdrew informed consent $(n=1)$. In the insulin glargine group, 491 patients were enrolled and three were excluded because of missing documentation of insulin treatment. The criteria for inclusion in the FAS were met by $78.3 \%(\mathrm{n}=1865)$ patients in the insulin detemir group and $70.9 \%(n=346)$ in the insulin glargine group. The criteria for inclusion in the EAS were met by $68.4 \%$ $(\mathrm{n}=1630)$ and $60.4 \%(\mathrm{n}=295)$ in the insulin detemir and insulin glargine groups, respectively.

A total of 571 (30.6\%) people in the detemir group discontinued the study for the following reasons: lost to follow up $(\mathrm{n}=355)$, OAD discontinued $(\mathrm{n}=12)$, addition of short-acting insulin $(\mathrm{n}=31)$, study drug used twice daily $(\mathrm{n}=21)$, study drug discontinued $(\mathrm{n}=27)$, other reasons $(\mathrm{n}=49)$ and missing data $(\mathrm{n}=106)$. In the glargine group, 155 (52.5\%) people were withdrawn for similar reasons: lost to follow-up $(\mathrm{n}=85)$, OAD discontinued $(n=4)$, addition of short-acting insulin $(n=9)$, study drug used twice daily $(\mathrm{n}=1)$, study drug discontinued $(n=7)$, other miscellaneous reasons $(n=16)$ and missing data $(n=40)$. Patients may have had more than one reason for discontinuing the study. 
The baseline characteristics of the patients of both groups are shown in Table 1. Baseline mean age, gender, weight, BMI, and previous medical history (including previous episodes of hypoglycaemia) were not significantly different between patients treated with insulin detemir and insulin glargine, and rates of hypoglycaemia were low in both groups ( 0.37 and 0.59 events per patient year, respectively). The group of patients treated with insulin detemir, however, had a significantly shorter duration of diabetes ( 8.1 vs. 8.6 years, $\mathrm{p}=0.03$ ), and a higher baseline $\mathrm{HbA}_{1 \mathrm{c}}$ ( 9.7 vs. $9.2 \%$, [83 vs. $77 \mathrm{mmol} / \mathrm{mol}$ ] $\mathrm{p}=0.003)$ compared with patients treated with insulin

Table 1 Baseline characteristics of patients initiated on insulin detemir or insulin glargine: SOLVE ${ }^{\mathrm{TM}}$ Turkish cohort

\begin{tabular}{|c|c|c|c|}
\hline & $\begin{array}{l}\text { Insulin } \\
\text { detemir }\end{array}$ & $\begin{array}{l}\text { Insulin } \\
\text { glargine }\end{array}$ & $p$ value \\
\hline N & 2395 & 491 & \\
\hline $\begin{array}{l}\text { Percentage completing the } \\
24 \text {-week study }(\%)\end{array}$ & $76.2 \%$ & $68.4 \%$ & \\
\hline Age (years) & $56.8 \pm 10.2$ & $56.6 \pm 10.3$ & 0.7979 \\
\hline Female (\%) & $57.2 \%$ & $59.5 \%$ & 0.3468 \\
\hline Duration of Diabetes (years) & $8.1 \pm 5.6$ & $8.6 \pm 5.4$ & 0.0279 \\
\hline Weight (kg) & $79.8 \pm 13.9$ & $78.5 \pm 13.0$ & 0.0606 \\
\hline $\mathrm{BMI}\left(\mathrm{kg} / \mathrm{m}^{2}\right)$ & $29.6 \pm 4.8$ & $29.6 \pm 4.8$ & 0.9541 \\
\hline \multicolumn{4}{|l|}{ Previous medical history (\%) } \\
\hline Microvascular disease & $30.0 \%$ & $31.6 \%$ & 0.4663 \\
\hline Macrovascular disease & $21.3 \%$ & $19.8 \%$ & 0.4347 \\
\hline Hypoglycaemia & $3.8 \%$ & $3.9 \%$ & 0.8940 \\
\hline $\mathrm{HbA}_{1 \mathrm{c}}(\%)$ & $9.72 \pm 1.74$ & $9.24 \pm 1.71$ & 0.0033 \\
\hline $\mathrm{HbA}_{1 \mathrm{c}}(\mathrm{mmol} / \mathrm{mol})$ & $83 \pm 19$ & $77 \pm 19$ & \\
\hline FBG $(\mathrm{mg} / \mathrm{dl})$ & $233 \pm 75$ & $221 \pm 68$ & 0.0989 \\
\hline FBG $(\mathrm{mmol} / \mathrm{l})$ & $12.9 \pm 4.2$ & $12.3 \pm 3.7$ & \\
\hline $\begin{array}{l}\text { Rate of minor Hypoglycaemia } \\
\text { (events ppy) }\end{array}$ & 0.37 & 0.59 & 0.0554 \\
\hline \multicolumn{4}{|l|}{$\begin{array}{l}\text { OAD Treatment at time of } \\
\text { Insulin Initiation (\%) }\end{array}$} \\
\hline Number of OADs & & & 0.0214 \\
\hline $1 O A D$ & $29.6 \%$ & $26.3 \%$ & \\
\hline 2 OADs & $45.0 \%$ & $51.8 \%$ & \\
\hline$>2$ OADs & $25.4 \%$ & $21.8 \%$ & \\
\hline \multicolumn{4}{|l|}{ Class of OAD } \\
\hline Metformin & $81.9 \%$ & $86.7 \%$ & 0.0100 \\
\hline Sulphonylureas & $55.5 \%$ & $52.0 \%$ & 0.1611 \\
\hline Glinides & $21.6 \%$ & $26.1 \%$ & 0.0279 \\
\hline Thiazolidinediones & $20.2 \%$ & $18.8 \%$ & 0.4745 \\
\hline a-glucosidase inhibitors & $18.0 \%$ & $10.8 \%$ & 0.0001 \\
\hline DPP-IV inhibitors & $1.8 \%$ & $2.7 \%$ & 0.2441 \\
\hline
\end{tabular}

Values are in mean \pm SD or percentage. glargine. The number and type of OADs used prior to insulin initiation also differed significantly between the groups, with a higher proportion of patients using a single OAD ( $30 \%$ vs. $26 \%$ ) or $>2$ OADs ( $25 \%$ vs. $22 \%$ ), in the group of patients initiating with insulin detemir (Table 2).

\section{Serious adverse drug reactions (SADRs) and adverse drug reactions (ADRs)}

SADRs, including major hypoglycaemia, were not reported during the observation period in either treatment group.

A single ADR was reported in the insulin detemir group (pruritus, skin and subcutaneous tissue disorder), and the relationship of this ADR to insulin detemir was determined as 'probable'. It was documented that the condition recovered, and that neither the therapy, nor the insulin dose was modified.

\section{Hypoglycaemia}

The incidence rate of minor hypoglycaemia increased significantly $(\mathrm{p}<0.001)$ in both groups from pre-insulin to final visit $(+0.66$ and +2.23 events per patient year in the detemir and glargine groups, respectively). Minor daytime hypoglycaemic events per patient year were 0.30 at baseline and 0.84 at final visit for insulin detemir, and 0.59 at baseline and 2.42 at final visit for insulin glargine. In the insulin detemir group, nocturnal hypoglycaemia occurred at a rate of 0.07 and 0.25 events per patient year at baseline and at final visit, respectively. In the insulin glargine group, the rate of nocturnal hypoglycaemia was 0 and 0.16 events per patient year at baseline and at final visit, respectively.

Insulin type was identified as an independent predictor of the occurrence of one or more episodes of hypoglycaemia during the study. After adjusting for the aforementioned confounders, insulin detemir had an odds ratio (OR) for hypoglycaemia of 0.33 [95\% CI $0.21,0.52$, $\mathrm{p}<0.001$ ] relative to insulin glargine (Figure 1a). The relationship between insulin type and risk of hypoglycaemia during the study remained consistent in the sensitivity analyses (see Additional file 1).

Table 2 Key insulin treatment related endpoints of patients on insulin detemir and insulin glargine at final visit: SOLVE ${ }^{T m}$ Turkish cohort (mean \pm SD)

\begin{tabular}{lll}
\hline & $\begin{array}{l}\text { Insulin } \\
\text { detemir }\end{array}$ & $\begin{array}{l}\text { Insulin } \\
\text { glargine }\end{array}$ \\
\hline $\mathrm{HbA}_{1 \mathrm{c}}(\%)$ & $7.48 \pm 1.19$ & $7.38 \pm 1.24$ \\
$\mathrm{HbA}_{1 \mathrm{C}}(\mathrm{mmol} / \mathrm{mol})$ & $58 \pm 13$ & $57 \pm 14$ \\
$\mathrm{FBG}(\mathrm{mg} / \mathrm{dl})$ & $145 \pm 44$ & $139 \pm 38$ \\
$\mathrm{FBG}(\mathrm{mmol} / \mathrm{l})$ & $8.0 \pm 2.4$ & $7.7 \pm 2.1$ \\
Weight $(\mathrm{kg})$ & $79.5 \pm 12.6$ & $79.7 \pm 12.2$ \\
Rate of Minor Hypoglycaemia (events ppy) & 1.08 & 2.56 \\
Insulin Dose $(\mathrm{U} / \mathrm{kg})$ & $0.30 \pm 0.13$ & $0.31 \pm 0.14$ \\
\hline
\end{tabular}




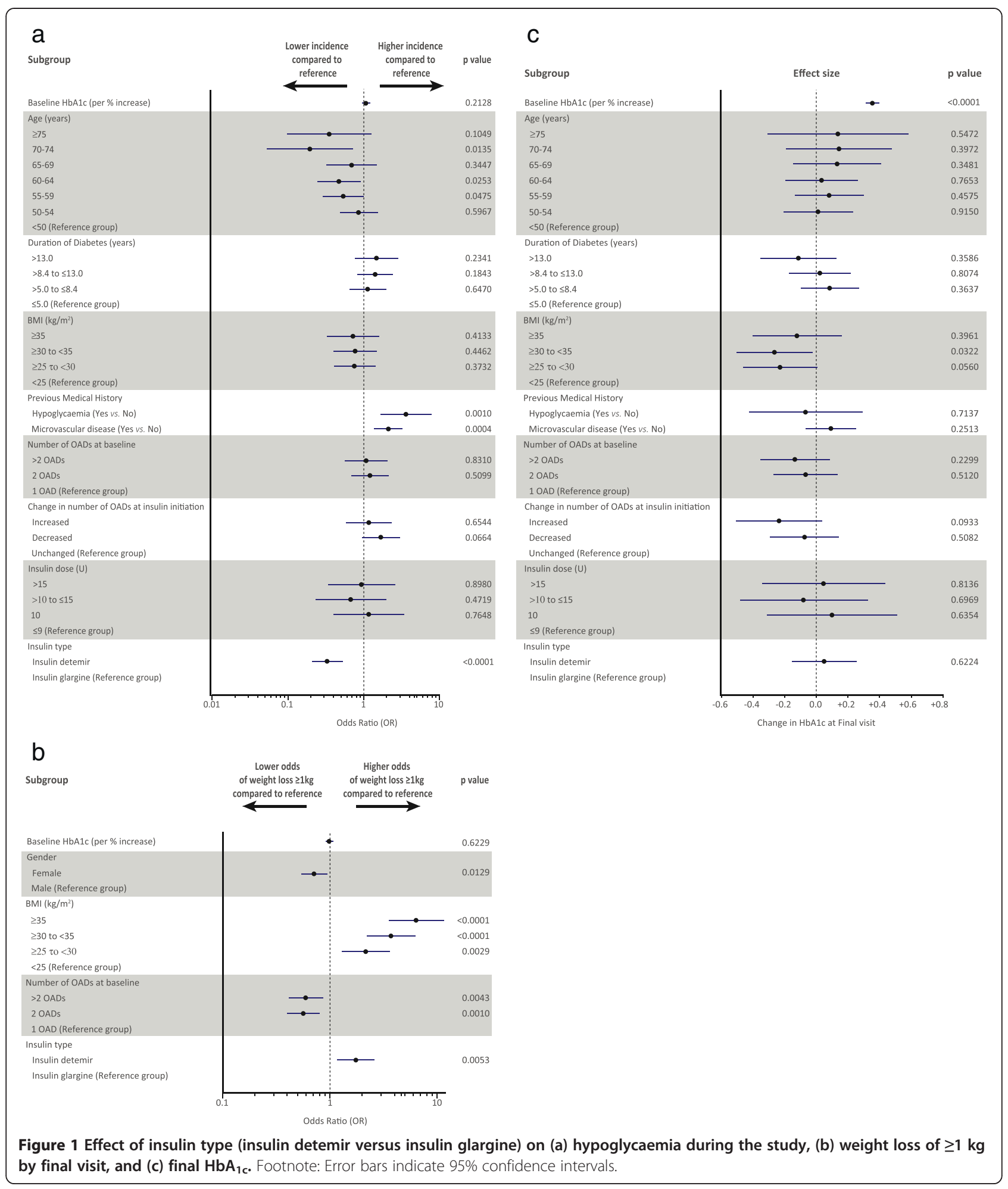

\section{Weight, BMI and lipids}

During the observational period, moderate weight loss was observed in patients treated with insulin detemir, with a mean change in weight of $-0.23 \mathrm{~kg}$ [95\% CI -0.49 , 0.02]. In contrast, patients in the insulin glargine group gained weight, with a mean weight change of $+1.55 \mathrm{~kg}$ [95\% CI 1.11, 2.00]. Insulin type was identified as an independent predictor for weight loss $\geq 1 \mathrm{~kg}$ during the study after adjustment for known confounders (Figure 1b). Insulin detemir was associated with significantly greater 
odds of weight loss $\geq 1 \mathrm{~kg}$ (OR 1.75 [95\% CI 1.18, 2.59; $\mathrm{p}=0.005]$ ) relative to insulin glargine.

Total cholesterol changed from $5.4 \pm 1.1 \mathrm{mmol} / \mathrm{l}$ at baseline to $5.1 \pm 1.0 \mathrm{mmol} / \mathrm{l}$ (change $-0.4 \mathrm{mmol} / \mathrm{l}$, [95\% CI $-0.5,-0.2], \mathrm{p}<0.001)$ in the insulin detemir group, and from $5.3 \pm 1.1 \mathrm{mmol} / \mathrm{l}$ to $4.7 \pm 0.9 \mathrm{mmol} / \mathrm{l}$ (change $0.6 \mathrm{mmol} / \mathrm{l},[95 \% \mathrm{CI}-0.9,-0.3], \mathrm{p}<0.001$ ) in patients treated with insulin glargine. Triglycerides changed from $2.3 \pm 1.3 \mathrm{mmol} / \mathrm{l}$ at baseline to $2.0 \pm 1.0 \mathrm{mmol} / \mathrm{l}$ (change $0.3 \mathrm{mmol} / \mathrm{l},[95 \% \mathrm{CI}-0.4,-0.1], \mathrm{p}<0.001)$ in the insulin detemir group, and from $2.3 \pm 1.2 \mathrm{mmol} / \mathrm{l}$ to $1.9 \pm$ $0.9 \mathrm{mmol} / \mathrm{l}$ (change $-0.4 \mathrm{mmol} / \mathrm{l},[95 \% \mathrm{CI}-0.6,-0.1$ ], $\mathrm{p}=0.01)$ in the insulin glargine group.

\section{Efficacy outcomes}

Results showed no major difference in $\mathrm{HbA}_{1 \mathrm{c}}$ values during the observational period between insulin glargine and insulin detemir (Table 1). At the final visit, $\mathrm{HbA}_{1 \mathrm{c}}$ had changed significantly $(\mathrm{p}<0.001)$ from the pre-insulin levels by $-2.21 \% \quad[95 \%$ CI $-2.32,-2.09] \quad(-24 \mathrm{mmol} / \mathrm{mol}$ [95\% CI $-25,-23])$ in the insulin detemir group, and by $-1.88 \%$ [95\% CI $-2.17,-1.59$ ] $\quad(-21 \mathrm{mmol} / \mathrm{mol}$ [95\% CI -24, -17]) in the insulin glargine group. Fasting blood glucose $(\mathrm{FBG})$ also changed significantly $(\mathrm{p}<0.001)$ from baseline to study end by $-90 \mathrm{mg} / \mathrm{dL}$ [95\% CI -97 , 83] $(-4.99 \mathrm{mmol} / \mathrm{l}[95 \% \mathrm{CI}-5.38,-4.60])$ in the insulin detemir group, and by $-83 \mathrm{mg} / \mathrm{dL}$ [95\% CI $-98,-68$ ] $(-4.61 \mathrm{mmol} / \mathrm{l}[-5.42,-3.79])$ in the insulin glargine group. All SMBG values improved significantly $(\mathrm{p}<0.05)$ over the study period in both patient groups (data not shown).

Regression analysis did not show insulin type to have an independent effect on the final $\mathrm{HbA}_{1 \mathrm{c}}$ value, with a difference of $+0.05 \%$ [ $95 \% \mathrm{CI}-0.15,+0.25 \%, \mathrm{p}=0.6$ ] $(+0.5 \mathrm{mmol} / \mathrm{mol}[95 \% \mathrm{CI}-1.6,+0.25])$ for insulin detemir relative to insulin glargine after adjustment for known confounders (Figure 1c). The relationship between insulin type and change in $\mathrm{HbA}_{1 \mathrm{c}}$ during the study remained consistent in the sensitivity analyses (see Additional file 1).

\section{Insulin dose}

Baseline and final doses of insulin detemir and insulin glargine were similar. The mean baseline dose was 0.21 $\mathrm{U} / \mathrm{kg}$ for both insulin types, and the mean dose at final visit was $0.30 \mathrm{U} / \mathrm{kg}$ for insulin detemir and $0.31 \mathrm{U} / \mathrm{kg}$ for insulin glargine.

\section{Discussion}

This international multicentre observational study was performed to document the safety and effectiveness of once-daily insulin detemir and insulin glargine in patients with T2DM managed in a real-life clinical practice setting in Turkey. The total incidence of ADRs in the population of 2,886 Turkish patients was low; with only one ADR observed during the 24-week study, and no SADRs or major hypoglycaemic episodes, despite significant improvements in glycaemic control.

According to a prospective 6-year follow-up study in a representative sample of Turkish men and women, the annual incidence rate of T2DM was 11.0 and 12.4 per 1000 person-years in women and men, corresponding to 300,000 incident cases annually [13]. A recently published report estimated the prevalence of diabetes in Turkey in people aged over 20 years to be $16.5 \%$, nearly half (45.5\%) of whom were newly diagnosed [14]. Another multinational survey of 100 physicians in Turkey examining the perceived role of healthcare providers in tackling T2DM and the challenges they face, particularly regarding insulin treatment also found that most physicians had seen an increase in the number of T2DM patients over the previous 5 years, and almost all participating physicians agreed that the burden of diabetes was increasing [15]. Despite the high prevalence of diabetes in Turkey, most primary care physicians rarely initiate, modify or intensify insulin therapy, with the lack of experience and time to educate patients often being cited as the main barriers [15].

The Turkish part of the SOLVE ${ }^{\mathrm{su}}$ study involved more than 200 participating physicians, and all treatment decisions were made at the discretion of the physician in accordance with patient's clinical requirements. Thus, the treatment of patients within the study may be considered to reflect real-life clinical practice in Turkey. Baseline demographic data indicate inadequate glycaemic control and delayed insulin initiation. The mean baseline $\mathrm{HbA}_{1 \mathrm{c}}$ (approximately 9.5\%) was well above the level of $7.0 \%$ recommended by the American Diabetes Association (ADA) [16]. Of all the countries participating in the SOLVE ${ }^{\text {rx }}$ study, Turkey had the highest proportion of patients with a baseline $\mathrm{HbA}_{1 \mathrm{c}} \geq 9.0 \%$ [10]. The mean diabetes duration of over 8 years at baseline also suggests delayed insulin initiation in this study population.

Basal insulin is a convenient and simple way to initiate insulin treatment in patients with T2DM. While there is general agreement that the currently available basal insulin analogue formulations are superior to human $\mathrm{NPH}$ insulin, in particular with respect to the risk of hypoglycaemia [17], there is no consensus as to which of the two available basal analogues should be recommended to initiate insulin treatment and what the potential differences are, if any, in patients with T2DM.

According to our knowledge, this is the first prospective non-interventional study to compare the effects of insulin detemir and insulin glargine in the real-life clinical environment. Several studies have compared either insulin detemir or insulin glargine with NPH insulin $[18,19]$, but there are few studies directly comparing both basal insulin analogues [20,21]. Consistent with our findings, most head-to-head treat-to-target trials have not shown a 
significant effect of insulin detemir versus insulin glargine on $\mathrm{HbA}_{1 \mathrm{c}}$ [20-22]. The only outlier is a recently published study by Meneghini et al. [23], which failed to confirm non-inferiority for insulin detemir versus insulin glargine. The lower than expected $\mathrm{HbA}_{1 \mathrm{c}}$ reductions in both groups $(-0.48 \%$ for insulin detemir and $-0.74 \%$ for insulin glargine) may be partly explained by the discontinuation of all OADs except metformin, without corresponding metformin dose adjustment and infrequent insulin dose titration.

Our safety results are consistent with other studies of once-daily insulin detemir initiation, both randomised controlled trials [24-26] and observational studies [27,28] in patients not responding to OAD therapy. These studies have consistently shown that insulin detemir has a good safety profile and a low incidence of hypoglycaemia. Randomised controlled trials comparing insulin detemir and insulin glargine have not reported significant differences in overall nocturnal and major hypoglycaemia rates [21,22], except for Meneghini et al. [23] where insulin detemir was associated with a significantly lower overall rate of hypoglycaemia. In this study, we report an independent effect of insulin type on the risk of minor hypoglycaemic episodes. As titration in this study was at the treating physicians' discretion, the difference in the incidence of hypoglycaemia in favour of the insulin detemir group may be partly because of the varying up-titration between the two groups and the slightly higher $\mathrm{HbA}_{1 \mathrm{c}}$ values at final visit $(7.48 \%$ vs. $7.38 \%)$ in patients treated with insulin detemir. However, reduced intra-patient glucose variability seen in patients treated with insulin detemir may also play a role [29-31]. Unlike some of the previous randomised controlled trials, where final insulin dose was found to be greater for insulin detemir compared with insulin glargine at the final visit [21-23], our data indicate similar end-of-study dose values between the two insulin analogues.

In the present study, insulin detemir also demonstrated a favourable weight-sparing effect, and was associated with higher odds (1.75-fold) of weight loss $\geq 1 \mathrm{~kg}$ compared with patients in the insulin glargine group. Actual mean weight change among insulin detemir patients was negative in contrast to insulin glargine-treated patients where the average weight increase was $1.5 \mathrm{~kg}$. These results are consistent with previously reported randomised controlled trials and observational study results showing a trend toward less weight gain in patients administered with insulin detemir [20-22,27,28,32]. The mechanism for the weight-sparing effect of insulin detemir is still not fully understood, but might be due to differences in albumin binding, liver sensitivity, glucose variability and hypoglycaemia, or satiety signalling [33].

The SOLVE ${ }^{\mathrm{mit}}$ study has several important limitations that have been described elsewhere [11]. Because the study was not randomised, it is not possible to differentiate between the effects of treatment and other study or demographic variables on clinical outcomes, and therefore, the results of this study should be interpreted with caution. While the regression models were used to control for various known confounders, additional factors such as the speed of insulin up-titration, dose and type of combination OAD therapy and other variations in local clinical practice, may also have influenced the efficacy and safety of these two basal insulin analogues. Patients were recruited into the study after they were deemed to be candidates for once-daily insulin detemir or once-daily insulin glargine as add-on therapies to OADs based on the decision of the study physician according to local clinical practice. The percentage of patients lost to follow-up in the Turkish cohort (in both insulin detemir and glargine groups) was larger than for the total SOLVE ${ }^{\mathrm{mm}}$ cohort [11]. Both the recruitment and the loss to follow-up infer selection bias. In addition, whereas the recall of severe hypoglycemia appears to be preserved for a period of up to 1 year, the reliability of recall of episodes of mild hypoglycemia is unknown in patients with T2DM, and may be subject to recall bias [34]. The definitions of hypoglycemia ( $<56 \mathrm{mg} / \mathrm{dL}$ or $3.1 \mathrm{mmol} / \mathrm{L})$ are consistent with other studies involving insulin detemir, and is a level at which autonomic symptoms of hypoglycemia are known to occur [35].

\section{Conclusion}

The results from the SOLVE ${ }^{\text {ma }}$ cohort in Turkey are consistent with previously reported randomised clinical trials and non-investigational study data of insulin detemir with regard to effective glycaemic control, low incidence of hypoglycaemia and a weight-sparing effect. Compared with T2DM patients initiated on insulin glargine in Turkey, insulin detemir was associated with a similar level of glycaemic control, but a lower risk of hypoglycaemia and greater odds of weight loss, after correction for a number of known confounders. This observational study provides useful additional information on the implementation and benefits of long-acting insulin analogues in a real-life clinical setting of Turkish patients with T2DM.

\section{Additional file}

Additional file 1: The results of sensitivity analyses on the effect of insulin type (insulin detemir vs. insulin glargine) on (A) hypoglycaemia during the study, and (B) final $\mathrm{HbA}_{1 \mathrm{c}}$.

\section{Competing interests}

Authors TD and JV have received financial support from Novo Nordisk to attend meetings to discuss the design, analysis and interpretation of the results of the SOLVE ${ }^{\mathrm{TM}}$ study.

TD has received consulting fees from Astra Zeneca, Bristol Meyers Squibb, Merck, Novo Nordisk and Sanofi-Aventis. RE has received consulting fees from Novo Nordisk. JV serves on advisory boards with Abbott Diabetes Care, 
Bristol Meyers Squibb, Johnson and Johnson, Lilly Industries, Merck, Novo Nordisk, Sanofi Aventis and Takeda Industries. JV has also received payment for lectures for Bristol Meyers Squibb, Daiichi-Sankyo, Lilly Industries and Novo Nordisk. JV's institution has received research grants from Lilly Industries and Novo Nordisk. ALS and TB are employees of Novo Nordisk.

\section{Authors' contributions}

TD and JV have been involved with the study from conception, providing input to the study design, protocol, pre-defined analyses and interpretation of global results. TD has also monitored the conduct of the study in Turkey. The manuscript outline was prepared during a meeting with all authors; and all authors have given subsequent input to the drafts of this manuscript, and have reviewed and approved all content. ALS performed and/or reviewed all statistical analyses.

\section{Authors' information}

TD was the national principal investigator for this study.

\section{Acknowledgements}

The authors would like to thank all investigators and patients for their participation in this study. Additionally, the authors thank Dr Christopher M. Burton of Point Of Care Medical Consulting for editorial assistance.

\section{Funding}

The study was funded by Novo Nordisk. Novo Nordisk has provided additional funds to cover data management and medical writing services.

\section{Author details}

${ }^{1}$ Department of Endocrinology, Diabetes and Metabolism, Cerrahpasa Medical School, Istanbul University, 34363 Istanbul, Turkey. ${ }^{2}$ Department of Endocrinology and Metabolic Diseases, Faculty of Medicine, Ankara University, Ibn-i Sina Hospital, Ankara, Turkey. ${ }^{3}$ Department of Biostatistics \& Epidemiology, Novo Nordisk A/S, Søborg, Denmark. ${ }^{4}$ Department of Clinical, Medical, \& Regulatory Affairs, Novo Nordisk Saglik Urunleri Tic. Ltd. Sti. Etiler-Istanbul, Turkey. ${ }^{5}$ Department of Diabetes and Endocrinology, Royal Liverpool University Hospital, Liverpool, UK.

Received: 11 July 2013 Accepted: 15 July 2014

Published: 21 July 2014

\section{References}

1. American Diabetes Association: Standards of medical care in diabetes2013. Diabetes Care 2013, 36(Suppl 1):S11-S66.

2. Hirsch IB: Intensifying insulin therapy in patients with type 2 diabetes mellitus. Am J Med 2005, 118(Suppl 5A):21S-26S.

3. Poon K, King AB: Glargine and detemir: Safety and efficacy profiles of the long-acting basal insulin analogs. Drug Healthc Patient Saf 2010, 2:213-223.

4. Jakobsen M, Dalsgaard M, Hormann M, Moller DV: Insulin analogues dosing and costs - comparing real-life daily doses of insulin detemir and insulin glargine in type 2 diabetes patients. BMC Endocr Disord 2012, 12:21.

5. Tsai ST, Pathan F, Ji L, Yeung VT, Chadha M, Suastika K, Son HS, Tan KE, Benjasuratwong Y, Nguyen TK, lqbal F: First insulinization with basal insulin in patients with Type 2 diabetes in a real-world setting in Asia. J Diabetes 2011, 3:208-216.

6. Gordon J, Pockett RD, Tetlow AP, McEwan P, Home PD: A comparison of intermediate and long-acting insulins in people with type 2 diabetes starting insulin: an observational database study. Int J Clin Pract 2010, 64:1609-1618.

7. Declaration of Helsinki: Ethical Principles for Medical Research Involving Human Patients. Edinburgh, Scotland: 52nd WMA General Assembly; 2000. Ref Type: Internet Communication.

8. International Society of Pharmacoepidemiology: Guidelines for good pharmacoepidemiology practices (GPP). Pharmacoepidemiol Drug Saf 2008, 17:200-208.

9. International Conference on Harmonisation of Technical Requirements for Registration of Pharmaceuticals for Human Use: ICH Harmonised Tripartite Guideline. Available online from http://www.ich.org/products/ guidelines/.
10. Khunti K, Damci T, Meneghini L, Pan CY, Yale JF: Study of Once Daily Levemir (SOLVE): insights into the timing of insulin initiation in people with poorly controlled type 2 diabetes in routine clinical practice. Diabetes Obes Metab 2012, 14:654-661.

11. Khunti K, Caputo S, Damci T, Dzida GJ, Ji Q, Kaiser M, Karnieli E, Liebl A, Ligthelm RJ, Nazeri A, Orozco-Beltran D, Pan C, Ross SA, Svendsen AL, Vora J, Yale JF, Meneghini LF: The safety and efficacy of adding once-daily insulin detemir to oral hypoglycaemic agents in patients with type 2 diabetes in a clinical practice setting in 10 countries. Diabetes Obes Metab 2012, 14:1129-1136

12. Caputo S, Andersen H, Kaiser M, Karnieli E, Meneghini LF, Svendsen AL: Effect of baseline HBA1C on glycemic control and diabetes management following initiation of once-daily insulin detemir in real-life clinical practice. Endocr Pract 2013, 19:462-470.

13. Onat A, Hergenc G, Uyarel H, Can G, Ozhan H: Prevalence, incidence, predictors and outcome of type 2 diabetes in Turkey. Anadolu Kardiyol Derg 2006, 6:314-321.

14. Satman I, Omer B, Tutuncu Y, Kalaca S, Gedik S, Dinccag N, Karsidag K, Genc S, Telci A, Canbaz B, Turker F, Yilmaz T, Cakir B, Tuomilehto J, TURDEP-II Study Group: Twelve-year trends in the prevalence and risk factors of diabetes and prediabetes in Turkish adults. Eur J Epidemiol 2013, 28:169-180.

15. Cuddihy RM, Philis-Tsimikas A, Nazeri A: Type 2 diabetes care and insulin intensification: is a more multidisciplinary approach needed? Results from the MODIFY survey. Diabetes Educ 2011, 37:111-123.

16. Inzucchi SE, Bergenstal RM, Buse JB, Diamant M, Ferrannini E, Nauck M, Peters AL, Tsapas A, Wender R, Matthews DR: Management of hyperglycemia in type 2 diabetes: a patient-centered approach: position statement of the American Diabetes Association (ADA) and the European Association for the Study of Diabetes (EASD). Diabetes Care 2012, 35:1364-1379.

17. Monami M, Marchionni N, Mannucci E: Long-acting insulin analogues versus NPH human insulin in type 2 diabetes: a meta-analysis. Diabetes Res Clin Pract 2008, 81:184-189.

18. Chapman TM, Perry CM: Insulin detemir: a review of its use in the management of type 1 and 2 diabetes mellitus. Drugs 2004, 64:2577-2595.

19. Horvath K, Jeitler K, Berghold A, Ebrahim SH, Gratzer TW, Plank J, Kaiser T, Pieber TR, Siebenhofer A: Long-acting insulin analogues versus NPH insulin (human isophane insulin) for type 2 diabetes mellitus. Cochrane Database Syst Rev 2007, 18:CD005613.

20. Mullins P, Sharplin P, Yki-Jarvinen H, Riddle MC, Haring HU: Negative binomial meta-regression analysis of combined glycosylated hemoglobin and hypoglycemia outcomes across eleven Phase III and IV studies of insulin glargine compared with neutral protamine Hagedorn insulin in type 1 and type 2 diabetes mellitus. Clin Ther 2007, 29:1607-1619.

21. Rosenstock J, Davies M, Home PD, Larsen J, Koenen C, Schernthaner G: A randomised, 52-week, treat-to-target trial comparing insulin detemir with insulin glargine when administered as add-on to glucose-lowering drugs in insulin-naive people with type 2 diabetes. Diabetologia 2008, 51:408-416.

22. Hollander P, Cooper J, Bregnhoj J, Pedersen CB: A 52-week, multinational, open-label, parallel-group, noninferiority, treat-to-target trial comparing insulin detemir with insulin glargine in a basal-bolus regimen with mealtime insulin aspart in patients with type 2 diabetes. Clin Ther 2008, 30:1976-1987.

23. Meneghini L, Kesavadev J, Demissie M, Nazeri A, Hollander P: Once-daily initiation of basal insulin as add-on to metformin: a 26-week, randomized, treat-to-target trial comparing insulin detemir with insulin glargine in patients with type 2 diabetes. Diabetes Obes Metab 2013, 15:729-736.

24. Holman RR, Thorne KI, Farmer AJ, Davies MJ, Keenan JF, Paul S, Levy JC, 4-T Study Group: Addition of biphasic, prandial, or basal insulin to oral therapy in type 2 diabetes. N Engl J Med 2007, 357:1716-1730.

25. Holman RR, Farmer AJ, Davies MJ, Levy JC, Darbyshire JL, Keenan JF, Paul SK, 4-T Study Group: Three-year efficacy of complex insulin regimens in type 2 diabetes. N Engl J Med 2009, 361:1736-1747.

26. Philis-Tsimikas A, Charpentier G, Clauson P, Ravn GM, Roberts VL, Thorsteinsson B: Comparison of once-daily insulin detemir with NPH insulin added to a regimen of oral antidiabetic drugs in poorly controlled type 2 diabetes. Clin Ther 2006, 28:1569-1581. 
27. Dornhorst A, Luddeke HJ, Sreenan S, Kozlovski P, Hansen JB, Looij BJ, Meneghini L: Insulin detemir improves glycaemic control without weight gain in insulin-naive patients with type 2 diabetes: subgroup analysis from the PREDICTIVE study. Int J Clin Pract 2008, 62:659-665.

28. Meneghini LF, Dornhorst A, Sreenan S: Once-daily insulin detemir in a cohort of insulin-naive patients with type 2 diabetes: a sub-analysis from the PREDICTIVE study. Curr Med Res Opin 2009, 25:1029-1035.

29. Haak T, Tiengo A, Draeger E, Suntum M, Waldhausl W: Lower withinsubject variability of fasting blood glucose and reduced weight gain with insulin detemir compared to NPH insulin in patients with type 2 diabetes. Diabetes Obes Metab 2005, 7:56-64.

30. Heise T, Pieber TR: Towards peakless, reproducible and long-acting insulins. An assessment of the basal analogues based on isoglycaemic clamp studies. Diabetes Obes Metab 2007, 9:648-659.

31. Tone A, Iseda I, Higuchi C, Tsukamoto K, Katayama A, Matsushita Y, Hida K, Wada J, Shikata K: Comparison of insulin detemir and insulin glargine on glycemic variability in patients with type 1 and type 2 diabetes. Exp Clin Endocrinol Diabetes 2010, 118:320-324.

32. Swinnen SG, Dain MP, Aronson R, Davies M, Gerstein HC, Pfeiffer AF, Snoek FJ, Devries JH, Hoekstra JB, Holleman F: A 24-week, randomized, treat-totarget trial comparing initiation of insulin glargine once-daily with insulin detemir twice-daily in patients with type 2 diabetes inadequately controlled on oral glucose-lowering drugs. Diabetes Care 2010, 33:1176-1178.

33. Hermansen K, Davies M: Does insulin detemir have a role in reducing risk of insulin-associated weight gain? Diabetes Obes Metab 2007, 9:209-217.

34. Zammitt NN, Frier BM: Hypoglycemia in type 2 diabetes: pathophysiology, frequency, and effects of different treatment modalities. Diabetes Care 2005, 28:2948-2961.

35. Swinnen SG, Mullins P, Miller M, Hoekstra JB, Holleman F: Changing the glucose cut-off values that define hypoglycaemia has a major effect on reported frequencies of hypoglycaemia. Diabetologia 2009, 52:38-41.

doi:10.1186/1472-6823-14-61

Cite this article as: Damci et al:: Lower risk of hypoglycaemia and greater odds for weight loss with initiation of insulin detemir compared with insulin glargine in Turkish patients with type 2 diabetes mellitus: local results of a multinational observational study. BMC Endocrine Disorders 2014 14:61.

\section{Submit your next manuscript to BioMed Central and take full advantage of:}

- Convenient online submission

- Thorough peer review

- No space constraints or color figure charges

- Immediate publication on acceptance

- Inclusion in PubMed, CAS, Scopus and Google Scholar

- Research which is freely available for redistribution 